\title{
Primary intestinal T-cell and NK-cell lymphomas: a clinicopathological and molecular study from China focused on type II enteropathy-associated T-cell lymphoma and primary intestinal NK-cell lymphoma
}

\author{
Jian Sun, Zhaohui Lu, Di Yang and Jie Chen
}

Department of Pathology, Peking Union Medical College Hospital, Chinese Academy of Medical Sciences and Peking Union Medical College, Beijing, People's Republic of China

\begin{abstract}
In China, which is a non-endemic area for celiac disease, primary intestinal T-cell and NK-cell lymphomas might comprise heterogeneous subtypes. Both type II enteropathy-associated T-cell lymphoma and primary intestinal NK-cell lymphoma are rarely reported and poorly characterized in China. In this study, we examined the clinicopathological and molecular features of $\mathbf{3 8}$ cases of primary intestinal T-cell and NK-cell lymphoma in Chinese patients. Based on these findings, we first classified the patients into an NK-cell group ( $n=6)$ and a T-cell group $(n=32)$. In the NK-cell group, the mean age was 37 years. All tumors of the NK-cell group were positive for Epstein-Barr virus encoded mRNA in the majority of tumor cells and were polyclonal according to the results of commercial BIOMED-2 T-cell receptor gene rearrangement assays. The survival in the NK-cell group was significantly worse than that of the T-cell group $(P=0.0247)$. Next, 7 tumors of the T-cell group were considered type II enteropathy-associated T-cell lymphoma, while 24 were considered peripheral T-cell lymphoma, not otherwise specified (NOS). In the type II enteropathy-associated T-cell lymphoma group, the mean age was 55 years. Type II enteropathy-associated T-cell lymphoma tumor cells from all seven patients were monomorphic, medium sized. The survival in the type II enteropathy-associated T-cell lymphoma group was significantly worse than that of the peripheral T-cell lymphoma, NOS group $(P=0.0181)$. Multivariate analysis identified NK-cell phenotype, male gender, and CD8 positivity as factors for poor prognosis in our series of primary intestinal T-cell and NK-cell lymphoma patients. In conclusion, most cases of primary intestinal T-cell and NK-cell lymphoma in China are not associated with celiac disease and could be classified to NK-cell group, type II enteropathy-associated T-cell lymphoma group, and peripheral T-cell lymphoma, NOS group. Each group has distinctive histopathological features with prognostic significance. Modern Pathology (2011) 24, 983-992; doi:10.1038/modpathol.2011.45; published online 18 March 2011
\end{abstract}

Keywords: enteropathy-associated T-cell lymphoma; intestine; NK-cell lymphoma; T-cell lymphoma

The gastrointestinal tract is the most common primary site of extranodal lymphomas, accounting for $30-50 \%$ of all primary extranodal lymphomas. ${ }^{1}$ The majority of these lymphomas have a B-cell

Correspondence: Dr J Chen, MD, PhD, Department of Pathology, Peking Union Medical College Hospital, Chinese Academy of Medical Sciences and Peking Union Medical College, 1 Shuai Fu Yuan Hu Tong, Beijing 100730, People's Republic of China. E-mail: xhblk@163.com

Received 10 October 2010; revised and accepted 13 December 2010; published online 18 March 2011 phenotype. ${ }^{2}$ Primary intestinal T-cell and NK-cell lymphomas are rare but more aggressive. Most cases of primary intestinal T-cell and NK-cell lymphoma in Europe are enteropathy-associated T-cell lymphomas that are a complication of celiac disease. ${ }^{3}$ However, celiac disease is very rare in East Asians, and only a few cases have been reported in this population. ${ }^{4,5}$

A variant of enteropathy-associated T-cell lymphoma was introduced into the 2008 World Health Organization (WHO) classification, termed the monomorphic variant of enteropathy-associated 
T-cell lymphoma or type II. Type II enteropathyassociated T-cell lymphoma appears to have a broader geographic distribution and is encountered in Asia and other regions where celiac disease is rare. ${ }^{6}$

Extranodal NK/T-cell lymphoma is more prevalent in Asians and is strongly associated with Epstein-Barr virus (EBV). Nasal-type extranodal NK/T-cell lymphomas may arise in the intestine. ${ }^{7-9}$ In China, which is a non-endemic area for celiac disease, primary intestinal T-cell and NK-cell lymphomas might comprise heterogeneous subtypes, such as type II enteropathy-associated T-cell lymphoma, primary intestinal NK-cell lymphoma, and peripheral T-cell lymphoma, not otherwise specified (NOS). To define the clinicopathological features of primary intestinal T-cell and NK-cell lymphoma in China, we examined the clinicopathological and molecular features of 38 cases. Based on these findings, we classified the lymphomas into different type groups according to the new WHO classification. Furthermore, we compared the clinicopathological and prognostic characteristics of the groups to determine the differences between lymphoma types.

\section{Materials and methods}

\section{Case Selection}

The records of 47 consecutive patients with intestinal T-cell and NK-cell lymphomas in the pathology files of the Department of Pathology, Peking Union Medical College Hospital, from 1999 to 2009 were reviewed. Of them, 42 cases met the inclusion criteria for primary intestinal lymphoma. ${ }^{10,11}$ Of the 42 cases, 38 were included in the study and 4 were excluded ( 2 cases of anaplastic large cell lymphoma and 2 cases with no tissue block available for analysis). The Ethics Committee of the Peking Union Medical College Hospital approved this study.

\section{Clinical Data}

Available data, including clinical presentations, therapeutic regimens, and follow-up information, were evaluated. Staging procedures included complete physical examination, computerized tomography, positron emission tomography scans of the chest and abdomen, and bone marrow aspiration and biopsy. The disease stages were assigned according to the modification of the classical Ann Arbor staging system by Musshoff ${ }^{12}$ for extranodal lymphomas.

\section{Morphology and Immunohistochemistry}

Surgically resected or biopsy specimens were fixed routinely in $10 \%$ buffered formalin, embedded in paraffin, and stained with hematoxylin and eosin (HE). All cases were reviewed by at least two pathologists who were unaware of the clinical data. Immunohistochemical analysis was performed on formalin-fixed, paraffin-embedded tissue sections. Staining for CD3 (clone LN10, Novocastra), CD5 (clone 4C7, Novocastra), CD8 (clone C8/144B, Dako), CD20 (clone L26, Novocastra), CD30 (clone 1G12, Novocastra), CD56 (clone 1B6, Novocastra), and CD79a (clone JCB117, Dako) was performed using a Ventana Benchmark XT instrument (Ventana, Tucson, AZ, USA). All other reagents were obtained from Ventana. Staining for $\beta \mathrm{F}-1$ (clone 8A3, Endogen), CD4 (clone 4B12, Novocastra), granzyme B (clone GrB-7, Dako), and TIA-1 (clone 26gA10F5, Immunotech) was performed using the Envision method. Appropriate positive and negative controls were tested for each antibody.

\section{EBV In Situ Hybridization}

EBV in situ hybridization was performed on paraffin sections from all cases together with positive and negative controls using the EBV-encoded Small RNA (EBER)-1/2 in situ Hybridization Kit (Triplex International Bioscience, China) with digoxigeninlabeled probes. The extent of EBER positivity was graded as follows: negative, $1+: 1$ to $<25 \%$ of cells with positive signal; $2+$ : from 25 to $49 \%$; $3+$ : from 50 to $74 \%$; and $4+: \geq 75 \%$.

\section{T-Cell Receptor Gene Rearrangement Studies}

T-cell receptor gene rearrangement studies were performed on DNA extracted from paraffin-embedded tissue by using the IdentiClone TCRB, TCRG, and TCRD Gene Clonality Assays with gel detection (InVivoScribe Technologies, San Diego, CA, USA). All samples yielding PCR products $\geq 300 \mathrm{bp}$ were subjected to the full set of T-cell clonality testing. T-cell receptor gene rearrangement studies were performed according to the standard assay procedure, and the sample results were evaluated according to assay instructions. Each PCR study was carried out in duplicate and included positive, negative, and no-template controls. After heteroduplex analysis, the PCR products were analyzed by electrophoresis on $8 \%$ nondenaturing polyacrylamide gels and photographed under ultraviolet light using AlphaImager (Alpha Innotech, San Leandro, CA, USA).

\section{Histological Definition of Enteropathy and Designation of T-Cell and NK-Cell Lineages}

Histological evidence of enteropathy was defined by an increase in the number of intestinal intraepithelial lymphocytes $(\geq 40$ lymphocytes per 100 epithelial cells) in the intestinal mucosa adjacent to the 
tumor. The HE-stained sections and CD3-, CD8-, and TIA-1-labeled sections were evaluated for intestinal intraepithelial lymphocyte count.

As for the designation of T-cell and NK-cell lineages, clonal T-cell receptor gene rearrangements, and/or $\beta$-F1-positive tumors were considered T-cell lymphomas. The tumors that were negative for $\beta \mathrm{F}-1$, positive for EBER in the majority of tumor cells $(3+$ or higher) and polyclonal for T-cell receptor gene rearrangements were considered NK-cell lymphomas.

\section{Statistical Analysis}

Correlations between the two groups were evaluated by the Fisher's two-tailed exact test. Survival curves were plotted using the Kaplan-Meier method, and $P$-values were calculated using the log-rank test. To evaluate the independent prognostic relevance of primary intestinal T-cell and NK-cell lymphoma, multivariate analysis using a Cox regression model was performed. Data were analyzed with SPSS software for Windows, version 15.0 (SPSS, Chicago, IL, USA). $P$-values $<0.05$ were accepted as significant.

\section{Results}

\section{Clinical Findings}

There were a total of 38 patients. All patients were Chinese. The age of the patients ranged from 15 to 72 years, with a mean age of 44 years. The overall maleto-female ratio was 1.7:1 (24/14). The most common symptoms were abdominal pain (18/38) and fever (17/38). Seventeen patients had history of chronic diarrhea. Among them, only one had suspected celiac disease. The remaining 37 patients did not have evidence of celiac disease. Twenty-six patients underwent surgical resection, and 12 patients only received an endoscopic exam and biopsy. The common reasons for surgical resection were perforation of the intestine $(15 / 26)$, intestinal hemorrhage (4/26), and intestinal obstruction (4/26).

According to the modification of the classical Ann Arbor staging system by Musshoff for extranodal lymphomas, there were 25 patients at stages I-II and 13 at stages III-IV. Thirteen patients underwent surgical resection and chemotherapy. Twelve received surgical resection only and 11 received chemotherapy only. One patient received surgical resection, chemotherapy, and additional radiotherapy. One patient received chemotherapy and additional radiotherapy. The follow-up period ranged from 0.5 to 94 months, with a mean of 11.8 months for all patients. During the follow-up period, 21 patients died of the disease, 1 patient died for other reasons, 6 were alive with disease, 3 were alive with no evidence of disease, and 7 were lost to follow-up. The 1-, 2-, and 5-year survival rates of these 38 patients were 41,24 , and $5 \%$, respectively.

\section{Pathological Findings}

The tumors involved the small intestine in 15 patients, the colon in 19, and both in 3 . The tumors of one patient involved the stomach, small intestine, and colon non-contiguously. Nineteen patients had multicentric tumors. Endoscopic findings and gross examinations showed that 28 cases presented with plaque-like infiltrative lesions with shallow ulceration and that 10 cases exhibited protruding masses. Sixteen patients presented with intestinal perforation (including one not known before surgery). All perforations were due to the invasion of tumor cells. Histologically, 25 cases consisted of medium-sized cells and 13 of medium to large or pleomorphic large cells. Features of enteropathy in the intestinal mucosa adjacent to the tumor were found in eight cases. All eight cases showed different degrees of villous atrophy and crypt hyperplasia. As for the case with clinically suspect celiac disease, moderate villous atrophy, and crypt hyperplasia were present, but the intestinal intraepithelial lymphocytes accounted for about 25 per 100 epithelial cells.

\section{Immunohistochemical, EBV In Situ Hybridization, and T-Cell Receptor Gene Rearrangement Findings}

Immunohistochemically, all 38 tumors expressed CD3 and were negative for CD20 and CD79a. The positive frequencies of the other antigens were as follows: TIA-1 (36/38, 95\%), granzyme B (17/38, $45 \%)$, CD56 (17/38, 45\%), $\beta \mathrm{F}-1$ (16/38, 42\%), CD30 (10/38, 26\%), CD8 (7/38, 18\%), and CD4 (5/38, $13 \%)$. Only three tumors expressed CD5. Eighteen $(47 \%)$ of 38 tumors were positive for EBER to varying degrees: $4+(n=3), 3+(n=4), 2+$ $(n=1)$, and $1+(n=10)$. In cases with $\geq 2+$ EBER positivity, the distribution of the CD20- or CD79apositive cells was distinct from that of EBERpositive cells. The tumor from the patient with clinical suspected celiac disease was positive for CD3 and negative for CD4, CD8, and CD56.

Among the 38 tumors, 10 exhibited DNA sizes $\geq 400 \mathrm{bp}, 22$ at $300 \mathrm{bp}$, and 6 at $200 \mathrm{bp}$. Thirty-two (84\%) tumors yielding PCR products of $\geq 300 \mathrm{bp}$ were subjected to the full set of T-cell clonality testing. Twenty-seven of these tumors were clonal. Six tumors with suboptimal DNA quality (200 bp) were also subjected to clonality examination, and only one tumor showed rearranged TCRD genes. The other five cases were polyclonal.

\section{Classification of Lymphomas}

First, the 38 tumors were classified into an NK-cell group $(n=6)$ and a T-cell group $(n=32)$. The tumors that were negative for $\beta \mathrm{F}-1$, positive for EBER in the majority of tumor cells $(3+$ or higher), and polyclonal for T-cell receptor gene rearrangements were considered NK-cell lymphomas $(n=6$, including one tumor with a DNA size of $200 \mathrm{bp}$ ). Thirty 
tumors with clonal T-cell receptor gene rearrangements and/or $\beta \mathrm{F}$-1-positive tumors were regarded as T-cell lymphomas. The remaining two tumors, with a DNA size of $200 \mathrm{bp}$, were also classified as T-cell lymphomas according to their CD56-negative and EBER 0/1 + phenotype.

Then, based on the histological evidence of enteropathy and immunohistochemical findings, seven tumors of the T-cell lymphoma group were considered type II enteropathy-associated T-cell lymphoma (excluding one tumor both associated with enteropathy and with a CD4-positive phenotype). The one from the patient with clinical suspected celiac disease was considered type I enteropathy-associated T-cell lymphoma. The remaining 24 tumors were considered peripheral T-cell lymphoma NOS.

\section{Differences Between the T-Cell Lymphoma Group and the NK-Cell Lymphoma Group}

The pertinent clinicopathological features of the different groups are listed in Table 1. In the NK-cell group, the mean age was 37 years. Five (83\%) patients presented with fever, perforation, stages I-II disease, and arose in the colon. All six tumors were positive for CD3 and TIA-1 and negative for CD4, CD8, and CD5 (Figure 1). All six tumors were positive for EBER in the majority of tumor cells ( $3+$ or higher). NK-cell lymphomas were all polyclonal for T-cell receptor gene rearrangements, including one tumor with suboptimal DNA quality.

In the T-cell group, the mean age was 45 years. Twelve (38\%), 11 (34\%), and 20 (63\%) patients presented with fever, perforation, and stages I-II disease, respectively. Only one tumor was positive for EBER in the majority of tumor cells $(3+$ or higher). All 27 T-cell lymphomas with optimal DNA quality were clonal for T-cell receptor gene rearrangements. One of the five T-cell lymphomas with suboptimal DNA quality was clonal.

During the follow-up period, five of six NK-cell lymphoma patients died of the disease. The median survival time was 5 months. Sixteen of 32 T-cell lymphoma patients died of the disease. The median survival time was 22 months. The cumulative

Table 1 Comparison of histological and clinical findings between different groups

\begin{tabular}{|c|c|c|c|c|c|c|}
\hline \multirow[t]{2}{*}{ Characteristics } & \multicolumn{3}{|c|}{$\begin{array}{c}\text { Primary intestinal T-cell and NK-cell } \\
\text { lymphoma }\end{array}$} & \multicolumn{3}{|c|}{$\begin{array}{l}\text { Primary intestinal T-cell } \\
\text { lymphoma }\end{array}$} \\
\hline & $\begin{array}{l}\text { NK-cell group } \\
\quad(\mathrm{n}=6)\end{array}$ & $\begin{array}{l}\text { T-cell group } \\
\quad(\mathrm{n}=32)\end{array}$ & $\mathrm{P}$-value ${ }^{\mathrm{b}}$ & $\begin{array}{l}\text { Type II EATL } \\
\quad(\mathrm{n}=7)\end{array}$ & $\begin{array}{l}\text { PTCL NOS } \\
\quad(\mathrm{n}=24)\end{array}$ & $\mathrm{P}$-value ${ }^{\mathrm{b}}$ \\
\hline Gender (male/female) & $5 / 1$ & $19 / 13$ & 0.383 & $4 / 3$ & $15 / 9$ & 1.000 \\
\hline Age $>60$ years & $0(0)$ & $7(22)$ & 0.569 & $2(29)$ & $5(21)$ & 0.642 \\
\hline Abdominal pain & $3(50)$ & $4(13)$ & 0.063 & $0(0)$ & $4(17)$ & 0.550 \\
\hline Fever & $5(83)$ & $12(38)$ & 0.071 & $3(43)$ & $9(38)$ & 1.000 \\
\hline Bloody stool & 4 (67) & $17(53)$ & 0.672 & $6(86)$ & $10(42)$ & 0.083 \\
\hline Chronic diarrhea & 1 (17) & $13(41)$ & 0.383 & $4(57)$ & $8(33)$ & 0.384 \\
\hline Multicentric & $3(50)$ & $16(50)$ & 1.000 & $6(86)$ & $9(38)$ & $0.037^{\mathrm{c}}$ \\
\hline Perforation & $5(83)$ & $11(34)$ & 0.065 & $5(71)$ & $6(25)$ & 0.067 \\
\hline Stage (I-II/III-IV) & $5 / 1$ & $20 / 12$ & 0.643 & $7 / 0$ & $12 / 12$ & $0.026^{\mathrm{C}}$ \\
\hline Resection only & $3(50)$ & $9(28)$ & 0.357 & $4(57)$ & $5(21)$ & 0.150 \\
\hline Non-resection & $0(0)$ & $12(38)$ & 0.149 & $1(14)$ & $10(42)$ & 0.372 \\
\hline $\begin{array}{l}\text { Macroscopic type (ulceration/protruding } \\
\text { mass) }\end{array}$ & $4 / 2$ & $24 / 8$ & 0.644 & $5 / 2$ & $18 / 6$ & 1.000 \\
\hline Tumor cell size (medium/medium to large) & $3 / 3$ & $10 / 22$ & 0.392 & $7 / 0$ & $14 / 10$ & 0.066 \\
\hline $\mathrm{CD} 4+$ & $0(0)$ & $5(16)$ & 0.570 & $0(0)$ & $5(21)$ & 0.562 \\
\hline CD8+ & $0(0)$ & $7(22)$ & 0.569 & $5(71)$ & $2(8)$ & $0.002^{\mathrm{C}}$ \\
\hline CD56+ & $5(83)$ & $12(38)$ & 0.071 & $7(100)$ & $5(21)$ & $<0.001^{\mathrm{c}}$ \\
\hline$\beta \mathrm{F}-1+$ & $0(0)$ & $15(47)$ & 0.063 & $4(57)$ & $11(46)$ & 0.685 \\
\hline CD5+ & $0(0)$ & $3(9)$ & 1.000 & $3(43)$ & $13(54)$ & 1.000 \\
\hline CD30+ & 1 (17) & $9(28)$ & 1.000 & $2(29)$ & 7 (29) & 1.000 \\
\hline Granzyme B+ & $4(67)$ & $13(41)$ & 0.378 & $3(43)$ & $10(42)$ & 1.000 \\
\hline TIA-1+ & $6(100)$ & $30(94)$ & 1.000 & 7 (100) & $22(92)$ & 1.000 \\
\hline EBER32+ & $6(100)$ & $2(6)$ & $<0.001^{\mathrm{c}}$ & $0(0)$ & $2(8)$ & 1.000 \\
\hline
\end{tabular}

EATL, enteropathy-associated T-cell lymphoma; PTCL NOS, peripheral T-cell lymphoma not otherwise specified.

a Do not including the one was suspected type I enteropathy-associated T-cell lymphoma.

${ }^{\mathrm{b}}$ Fisher's exact test (two-tailed).

${ }^{\mathrm{C}}$ Statistically significant.

Figure 1 Morphology of primary intestinal NK-cell lymphoma and peripheral T-cell lymphoma NOS. (a-d) Histology, immunophenotype, and EBER in situ hybridization of a primary intestinal NK-cell lymphoma. At medium power, tumor cells of NK-cell lymphoma are small to medium sized (a), negative for $\beta \mathrm{F}-1$ (b), positive for CD56 (c), and positive for EBER in the majority of tumor cells (d). (e-h) Histology, immunophenotype, and EBER in situ hybridization of a peripheral T-cell lymphoma NOS. At medium power, tumor cells of this case of peripheral T-cell lymphoma NOS are medium to large sized (e), positive for $\beta$ F-1 (f), and negative for CD56 (g) and have scattered EBER-positive cells (h). 

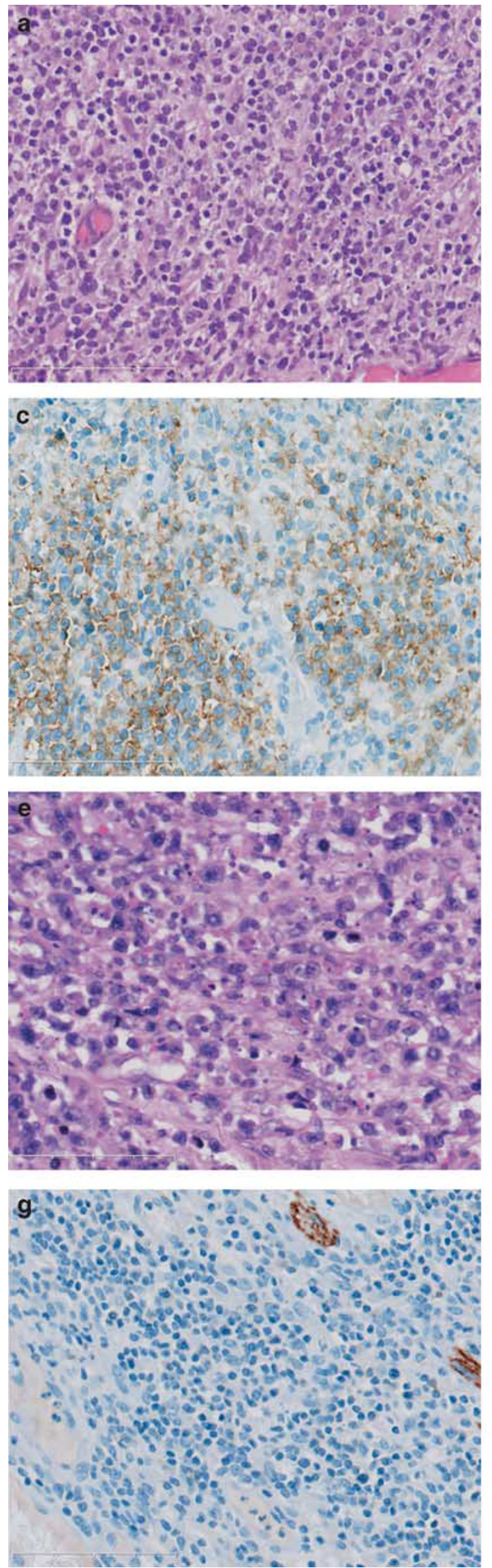
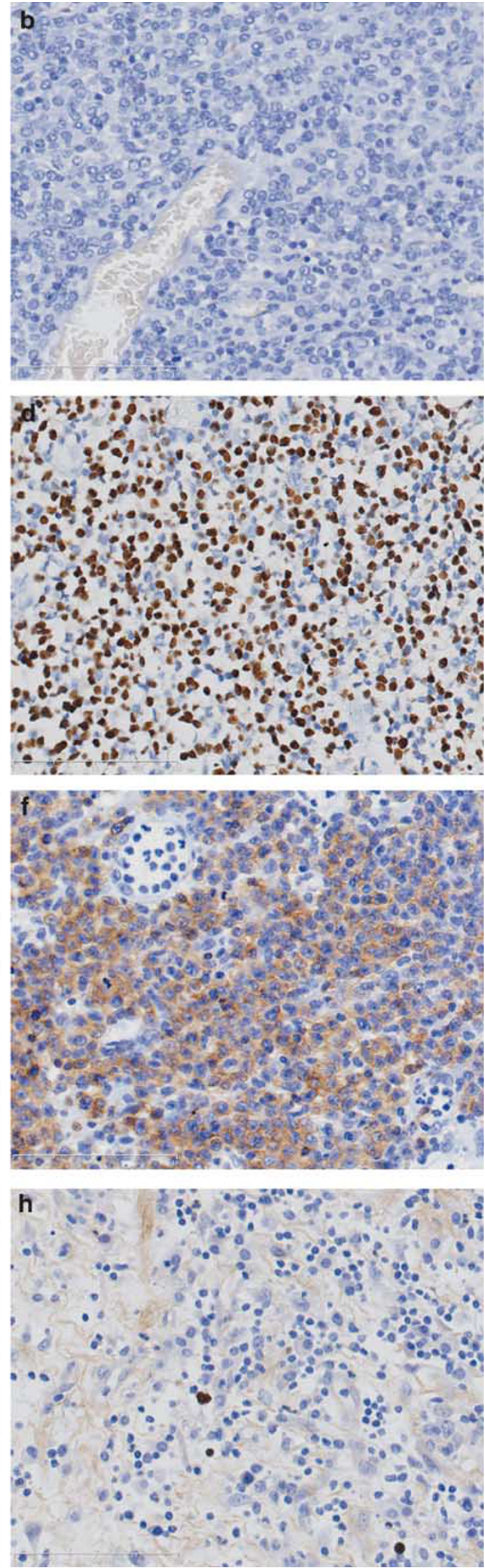


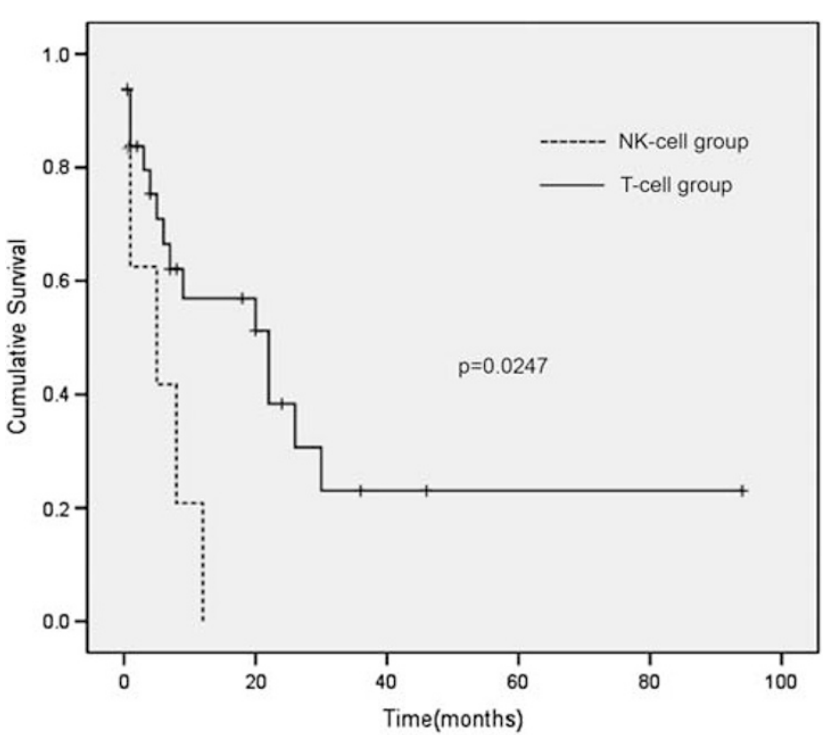

Figure 2 Kaplan-Meier survival curves and log-rank test for cumulative survival of the NK-cell group and the T-cell group are shown. The cumulative survival rate of the NK-cell group $(n=6)$ was significantly worse than that of the T-cell group $(n=32)$.

survival rate of the NK-cell group was significantly worse than that of the T-cell group $(P=0.0247)$ (Figure 2).

\section{Differences Between Type II Enteropathy-Associated T-Cell Lymphoma and Peripheral T-Cell Lymphoma NOS}

The mean age of the seven type II enteropathyassociated T-cell lymphoma patients was 55 years. Six $(86 \%)$ patients had bloody stool and multicentric tumors. All type II enteropathy-associated T-cell lymphomas were stages I-II, and the tumor cells were monomorphic and medium sized (Figure 3). Five tumors were positive for both CD8 and CD56, while two were only positive for CD56. Six tumors were negative for EBER, and one had an EBER score of $1+$.

The mean age of the 24 peripheral T-cell lymphoma NOS patients was 44 years. Differences between type II enteropathy-associated T-cell lymphoma and peripheral T-cell lymphoma NOS were evaluated by Fisher's two-tailed exact test. Among all characteristics, type II enteropathy-associated T-cell lymphoma was more likely to be multicentric $(P=0.037)$, stages I-II $(P=0.026)$, CD8 positivity $(P=0.002)$, and CD56 positivity $(P<0.001)$. Kaplan-Meier survival curves and log-rank test for cumulative survival showed that the cumulative survival rate in the type II enteropathy-associated T-cell lymphoma group was significantly worse than that of the peripheral T-cell lymphoma NOS group $(P=0.0181)$ (Figure 4).

\section{Multivariate Analysis}

The analysis of prognostic factors using the Cox proportional hazards regression model showed that male gender $(P=0.004)$, CD8 positivity $(P=0.004)$, CD56 positivity $(P=0.004)$, perforation $(P=0.014)$, stages I-II disease $(P=0.014)$, NK-cell phenotype $(P=0.028)$, and type II enteropathy-associated T-cell lymphoma $(P=0.041)$ were associated with poor prognosis in the univariate analysis in our series of primary intestinal T-cell and NK-cell lymphoma patients, whereas patient age, symptoms, management differences, the other cell surface markers, and the extent of EBER positivity were not. Multivariate analysis identified NK-cell phenotype (OR 6.482; 95\% CI: $1.726-24.351 ; P=0.006$ ), male gender (OR 5.601; 95\% CI: $1.712-18.328 ; P=0.004)$, and CD8 positivity (OR 10.960; 95\% CI: 2.747-43.736; $P=0.001$ ) as factors for poor prognosis.

\section{Discussion}

Extranodal NK/T-cell lymphoma is designated 'NK/ $\mathrm{T}$ ' (instead of 'NK') because some cases show a cytotoxic T-cell phenotype, although most cases appear to be genuine NK-cell neoplasms. These two types of lymphoma have been difficult to distinguish in the past because of limited access to comprehensive immunohistochemical and DNA analysis techniques. By definition, true NK-cell lymphoma does not show rearrangement of the T-cell receptor gene. Therefore, NK-cell lymphoma can be distinguished from NK-like peripheral T-cell lymphoma by reliable clonality testing of T-cell receptor genes. However, worldwide, many different PCR protocols and many different primers are used, each with a different sensitivity and applicability. The newly developed BIOMED-2 multiplex PCR assay represents a new approach to PCR-based clonality testing and greatly increases the diagnostic accuracy of Ig and T-cell receptor gene rearrangement detection. ${ }^{13}$

In our study, we chose the newly developed BIOMED-2 T-cell receptor gene rearrangement assays to assess the clonality of 38 paraffin-embedded primary intestinal T-cell and NK-cell lymphoma cases. Thirty-two (84\%) tumors yielded PCR products of $\geq 300 \mathrm{bp}$. The percentage was similar to that in Liu's ${ }^{14}$ study of 316 paraffin-embedded cases using the same protocol. Among 32 lymphomas with optimal DNA quality, all 5 NK-cell lymphomas were polyclonal for T-cell receptor gene rearrangements, and all 27 T-cell lymphomas were clonally. The overall sensitivity and specificity of the combined BIOMED-2 T-cell receptor gene rearrangement assays were both $100 \%$.

Although NK-cell lymphoma is prevalent in Asians, ${ }^{15}$ primary intestinal NK-cell lymphoma is extremely rare and highly aggressive, with short survival times. Most primary intestinal NK-cell lymphoma patients in our study were middle-aged 
a
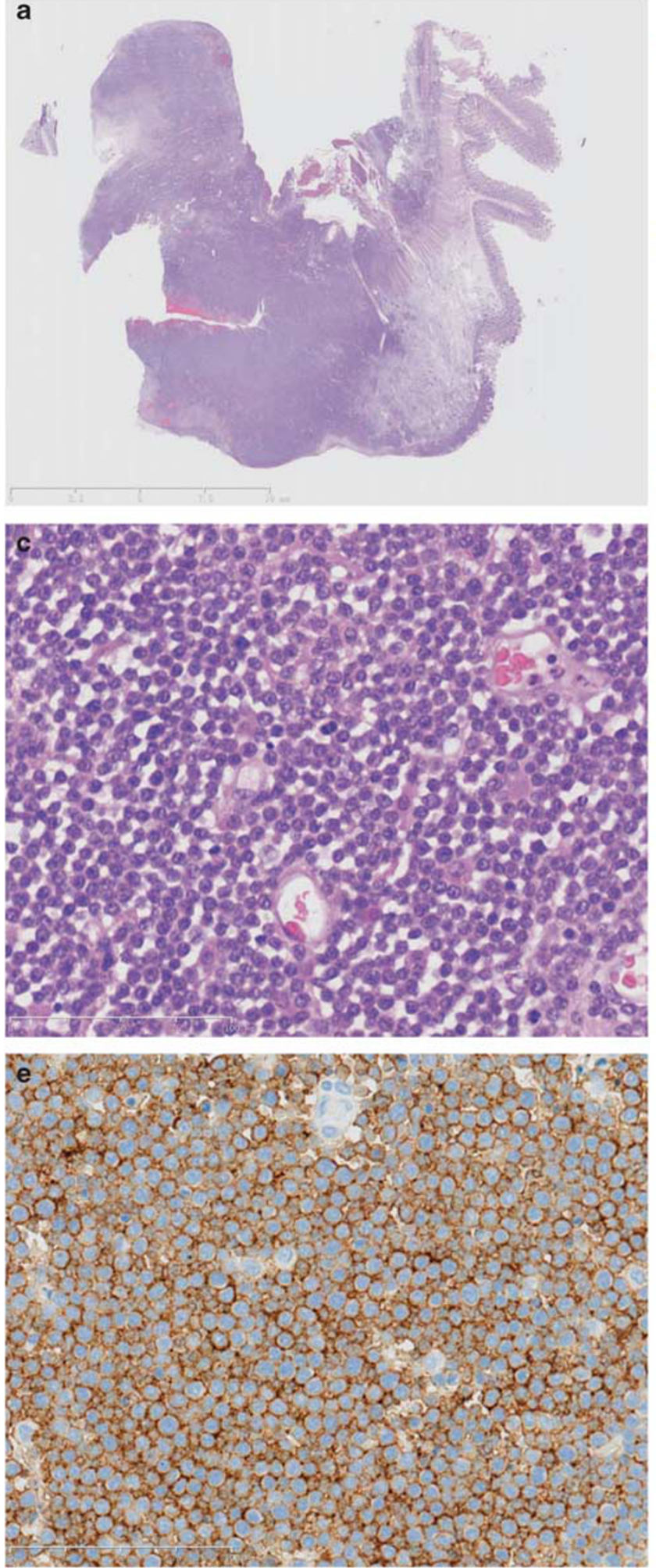
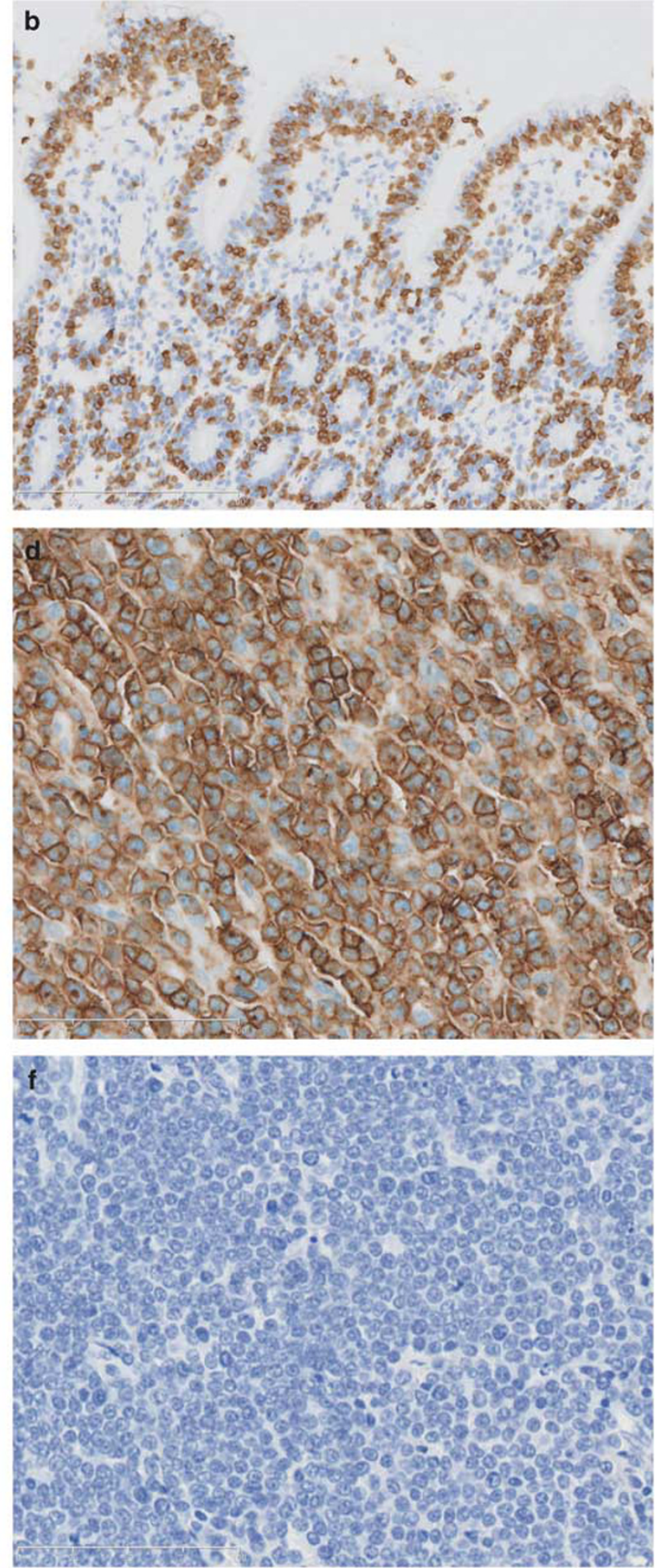

Figure 3 Histology, immunophenotype, and EBER in situ hybridization of a type II enteropathy-associated T-cell lymphoma. (a) Under low power, the type II enteropathy-associated T-cell lymphoma shows mucosal ulceration and diffuse lymphomatous infiltration through the intestinal wall. (b) Staining for CD3 shows an obvious increase in intestinal intraepithelial lymphocytes in the intestinal mucosa adjacent to the tumor. (c) Tumor cells of type II enteropathy-associated T-cell lymphoma are monomorphic and medium sized at medium power. (d) CD8 and (e) CD56 show diffuse positivity. (f) No EBER-positive cells were observed in this case. 


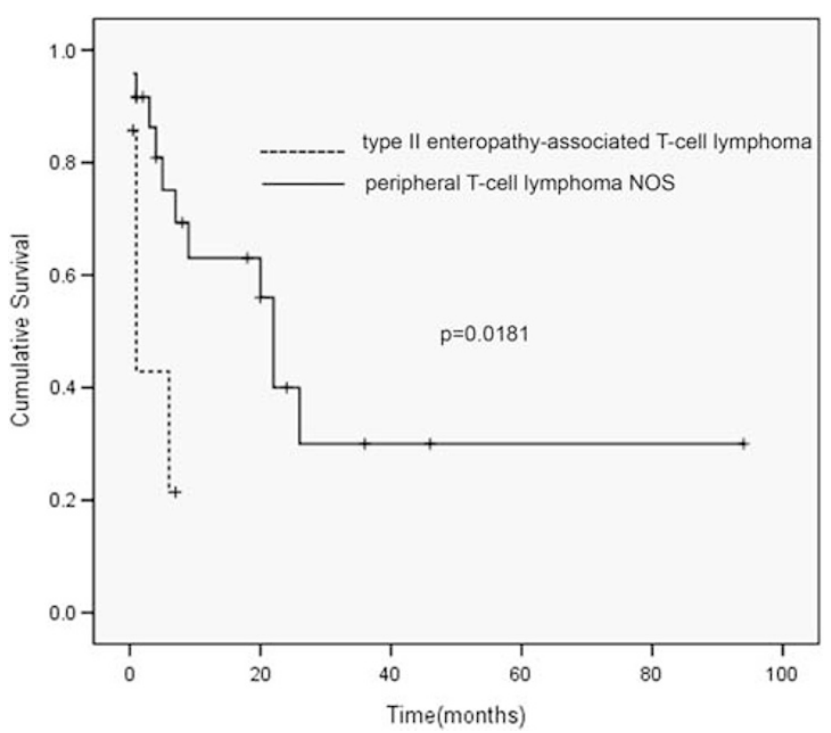

Figure 4 Kaplan-Meier survival curves and log-rank test for cumulative survival showed that the cumulative survival rate in the type II enteropathy-associated T-cell lymphoma group $(n=7)$ was significantly worse than that of the peripheral T-cell lymphoma NOS group $(n=24)$.

males (mean age 37 years), and the lymphomas were more likely to arise in the colon. As same as previous reports, ${ }^{7,16}$ primary intestinal NK-cell lymphoma in our study had a higher incidence of intestinal perforation and was more likely to cause systemic symptoms such as fever compared with the T-cell group. In 2008, Tung et $a 1^{17}$ reported five primary intestinal NK-cell lymphomas based on EBER positivity and polyclonal T-cell receptor gene rearrangements using conventional clonality studies in a series of 11 primary intestinal T-cell and NKcell lymphomas. The prognoses of the NK-cell and T-cell groups of their series did not differ significantly. In 2009, Chuang et al ${ }^{16}$ found $6(20 \%)$ cases of primary intestinal NK-cell lymphoma in their series of 30 primary intestinal T-cell and NK-cell lymphomas, and the NK-cell group had a worse prognosis on average. We used the same methods to designate T-cell and NK-cell lineages as Chuang et al. In our study, BIOMED-2 T-cell receptor gene rearrangement assays were used to test the clonality of each case. We found that the cumulative survival rate in the NK-cell group was significantly worse than that of the T-cell group. These results suggest that BIOMED-2 primers are superior to the conventional ones for T-cell clonality and reliably classify T-cell and NK-cell lineages.

Among primary intestinal T-cell and NK-cell lymphomas, enteropathy-associated T-cell lymphoma is the most characteristic. According to the WHO classification of hematological malignancies, enteropathy-associated T-cell lymphoma can be divided into two groups. Type II enteropathy-associated T-cell lymphoma accounts for $10-20 \%$ of enteropathy-associated T-cell lymphoma cases. As type II enteropathy-associated T-cell lymphoma was introduced, several reports about this lymphoma from East Asia have been published. ${ }^{17-19}$ In these reports, none of the patients had gluten-sensitive malabsorption syndrome. The definition of enteropathy varies among studies ${ }^{17,20}$ and may influence the lymphoma classification. The histological evidence of enteropathy in our study was defined solely by an increase of intestinal intraepithelial lymphocytes in the intestinal mucosa adjacent to the tumor. However, all defined enteropathy cases showed different degrees of villous atrophy and crypt hyperplasia. In our study, seven tumors were considered type II enteropathy-associated T-cell lymphoma, accounting for 16 and $22 \%$ of the primary intestinal T-cell and NK-cell lymphoma and T-cell groups, respectively. These percentages are higher than those reported by Chuang et al, ${ }^{16}$ who found only 2 type II enteropathy-associated T-cell lymphoma cases among 30 primary intestinal T-cell and NK-cell lymphomas.

The mean age of the six type II enteropathyassociated T-cell lymphoma cases in our study was 55 years, which was older than the average age of the primary intestinal NK-cell lymphoma patients. Classical (type I) enteropathy-associated T-cell lymphoma in the West occurs most commonly in the small intestine and less frequently in the colon or stomach. ${ }^{21}$ However, in our study, only two of seven type II enteropathy-associated T-cell lymphoma cases were confined to the small intestine. Two occurred in the colon, two occurred both in the small intestine and colon, and one involved the stomach, small intestine, and colon non-contiguously. A similar result was obtained by Ko et al, ${ }^{18}$ who found that only two of eight type II enteropathy-associated T-cell lymphoma cases were confined to the small intestine. These results suggest that, unlike most type I enteropathy-associated T-cell lymphoma cases were confined to the small intestine, type II enteropathy-associated T-cell lymphoma was more likely to occur in the ileocecum and the colon. According to previous studies, the prognosis of enteropathy-associated T-cell lymphoma is very poor and shows no difference between type I and type II. ${ }^{20}$ However, until now, no report has directly compared the differences in prognosis between enteropathy-associated T-cell lymphoma and other primary intestinal T-cell lymphomas in the same study. Our data showed that the cumulative survival rate in the type II enteropathy-associated T-cell lymphoma group was significantly worse than that of the peripheral T-cell lymphoma NOS group.

In our study, one tumor from a patient with suspected celiac disease, in the T-cell lymphoma group, was considered type I enteropathy-associated T-cell lymphoma. Due to limited evidence of celiac disease and the availability of only a biopsy specimen, this case was not compared further with other types of lymphoma. It is generally believed that 
celiac disease is very rare in East Asians. However, this conclusion has not been confirmed by largescale serological screening in this region. In a recent study in China, ${ }^{22} 4$ of 62 patients with chronic diarrhea were diagnosed with celiac disease based on capsule endoscopy findings, duodenal biopsies, and reaction to a gluten-free diet. The authors proposed that in China, especially in the northern area, where wheat is the main food, celiac disease might not be uncommon. Because the clinical range of celiac disease is wide and because some patients can be asymptomatic, the diagnosed patients could represent only a small portion of the true number of celiac disease patients among this population.

Sixteen (42\%) primary intestinal T-cell and NKcell lymphoma patients presented with intestinal perforation in our study. Both primary intestinal NK-cell lymphoma and type II enteropathy-associated T-cell lymphoma had high perforation rates (83 and $71 \%$, respectively). This might explain that why perforation was a poor prognostic factor in the univariate analysis but not in the multivariate analysis. In contrast with only 50\% patients of peripheral T-cell lymphoma NOS at stages I-II in our series, 100 and $83 \%$ patients of type II enteropathy-associated T-cell lymphoma and primary intestinal NK-cell lymphoma, respectively, were at stages I-II. Because both type II enteropathy-associated T-cell lymphomas and primary intestinal NKcell lymphomas behave in a highly aggressive manner, they might be more likely to present with perforation and be found in an early stage.

In previous studies, about 90 and $80 \%$ of type II enteropathy-associated T-cell lymphomas were positive for CD56 and CD8, respectively, ${ }^{21}$ and most intestinal NK-like T-cell lymphomas showed CD8 expression. ${ }^{16,23}$ In our study, the rates of CD56 expression in primary intestinal NK-cell lymphomas, type II enteropathy-associated T-cell lymphomas, and peripheral T-cell lymphoma NOS were 83 , 100 , and $20 \%$, respectively. As for CD8, the rates were 0,71 , and $2 \%$, respectively. Most CD8-positive cases were type II enteropathy-associated T-cell lymphoma, which had poor prognosis. Primary intestinal NK-cell lymphomas were all negative for CD8. Among the T-cell group, type II enteropathyassociated T-cell lymphoma was significantly associated with CD8 expression $(P=0.002)$ and CD56 expression $(P<0.001)$. Moreover, CD8 expression was a poor prognostic factor in multivariate analysis of all of our primary intestinal T-cell and NK-cell lymphoma cases. Male sex was also a poor prognostic factor in the multivariate analysis. This is the first report to include three different types of tumors with at least six cases of each. Therefore, our results are more likely to represent the general characteristics of primary intestinal T-cell and NK-cell lymphoma.

In conclusion, primary intestinal T-cell and NKcell lymphomas in China are a heterogeneous group of malignant lymphomas that includes type II enteropathy-associated T-cell lymphoma, primary intestinal NK-cell lymphoma, and peripheral T-cell lymphoma NOS. We can reliably separate these types using BIOMED-2 T-cell clonality assays, EBER positivity, histological evidence of enteropathy, and other clinicopathological features. Our data suggest that different types of primary intestinal T-cell and NK-cell lymphoma have distinctive histopathological features with prognostic significance. Both type II enteropathy-associated T-cell lymphoma and primary intestinal NK-cell lymphoma were highly aggressive lymphomas.

\section{Acknowledgements}

We thank Ms Yufeng Luo and Ms Qing Ling for their technical support. This study was supported by grants 2006BAI02A14 of 11th Five-Year Plan scientific and technological support from the Ministry of Science and Technology of the Peoples' Republic of China and the Scientific Research Special Projects of Health Industry of China (grant 200802011).

\section{Disclosure/conflict of interest}

The authors declare no conflict of interest.

\section{References}

1 Isaacson PG, Du MQ. Gastrointestinal lymphoma: where morphology meets molecular biology. J Pathol 2005;205:255-274.

2 Nakamura S, Matsumoto $\mathrm{T}$, Iida $\mathrm{M}$, et al. Primary gastrointestinal lymphoma in Japan: a clinicopathologic analysis of 455 patients with special reference to its time trends. Cancer 2003;97:2462-2473.

3 Verbeek WH, Van De Water JM, Al-Toma A, et al. Incidence of enteropathy-associated T-cell lymphoma: a nation-wide study of a population-based registry in The Netherlands. Scand J Gastroenterol 2008;43: 1322-1328.

4 Makishima H, Ito T, Kodama R, et al. Intestinal diffuse large B-cell lymphoma associated with celiac disease: a Japanese case. Int J Hematol 2006;83:63-65.

5 Lok KH, Yeung HC, Li KF, et al. Refractory celiac disease: an unusual disease in a Chinese patient. J Dig Dis 2008;9:238-240.

6 Isaacson PG, Chott A, Ott G, et al. Enteropathyassociated T-cell lymphoma. In: Swerdlow SH, Campo E, Harris NL, Jaffe ES, Pileri SA, Stein H, Vardiman JW (eds). WHO Classification of Tumors of Haematopoietic and Lymphoid Tissues. IARC: Lyon, 2008, pp 289-291.

7 Wan $\mathrm{M}$, Chow J, Lei $\mathrm{K}$, et al. Allelotyping of gastrointestinal nasal-type NK/T-cell lymphoma. Leuk Res 2004;28:339-343.

8 Moubayed P, Leithauser F, Binder T, et al. Two cases of primary malignant NK/T-cell lymphoma in the small intestine following an aggressive clinical course: Morphological, immunohistochemical, and molecular analysis. Leuk Lymphoma 2007;48:1451-1455. 
9 Wakabayashi S, Arai A, Oshikawa G, et al. Extranodal NK/T cell lymphoma, nasal type, of the small intestine diagnosed by double-balloon endoscopy. Int J Hematol 2009;90:605-610.

10 Fenoglio-Preiser CM, Noffsinger AE, Stemmermann GN, et al. (eds). Gastrointestinal Pathology: An Atlas and Text, 3rd edn. Lippincott Williams and Wilkins: Philadelphia, 2008, pp 1161-1202.

11 Boot H. Diagnosis and staging in gastrointestinal lymphoma. Best Pract Res Clin Gastroenterol 2010;24: 3-12.

12 Musshoff K. Clinical staging classification of nonHodgkin's lymphomas (author's transl). Strahlentherapie 1977;153:218-221.

13 van Krieken JH, Langerak AW, Macintyre EA, et al. Improved reliability of lymphoma diagnostics via PCR-based clonality testing: report of the BIOMED-2 Concerted Action BHM4-CT98-3936. Leukemia 2007;21:201-206.

14 Liu H, Bench AJ, Bacon CM, et al. A practical strategy for the routine use of BIOMED-2 PCR assays for detection of $\mathrm{B}$ - and T-cell clonality in diagnostic haematopathology. Br J Haematol 2007;138:31-43.

$15 \mathrm{Au}$ WY, Ma SY, Chim CS, et al. Clinicopathologic features and treatment outcome of mature T-cell and natural killer-cell lymphomas diagnosed according to the World Health Organization classification scheme: a single center experience of 10 years. Ann Oncol 2005;16:206-214.

16 Chuang SS, Chang ST, Chuang WY, et al. NK-cell lineage predicts poor survival in primary intestinal
NK-cell and T-cell lymphomas. Am J Surg Pathol 2009;33:1230-1240.

17 Tung CL, Hsieh PP, Chang JH, et al. Intestinal T-cell and natural killer-cell lymphomas in Taiwan with special emphasis on 2 distinct cellular types: natural killer-like cytotoxic T cell and true natural killer cell. Hum Pathol 2008;39:1018-1025.

18 Ko YH, Karnan S, Kim KM, et al. Enteropathyassociated T-cell lymphoma-a clinicopathologic and array comparative genomic hybridization study. Hum Pathol 2010;41:1231-1237.

19 Chuang SS, Liao YL, Liu $\mathrm{H}$, et al. The phenotype of intraepithelial lymphocytes in Taiwanese enteropathy-associated T-cell lymphoma is distinct from that of the West. Histopathology 2008;53: 234-236.

20 Chott A, Haedicke W, Mosberger I, et al. Most CD56+ intestinal lymphomas are CD8+CD5-T-cell lymphomas of monomorphic small to medium size histology. Am J Pathol 1998;153:1483-1490.

21 Zettl A, deLeeuw R, Haralambieva E, et al. Enteropathy-type T-cell lymphoma. Am J Clin Pathol 2007;127:701-706.

22 Jiang LL, Zhang BL, Liu YS. Is adult celiac disease really uncommon in Chinese? J Zhejiang Univ Sci B 2009;10:168-171.

23 Akiyama T, Okino T, Konishi H, et al. CD8+, CD56+ (natural killer-like) T-cell lymphoma involving the small intestine with no evidence of enteropathy: clinicopathology and molecular study of five Japanese patients. Pathol Int 2008;58:626-634. 